\title{
LA LIBRE COMPETENCIA ECONÓMICA EN EL DERECHO COLOMBIANO: UNA REVISIÓN DESDE LA ECONOMÍA SOCIAL DE MERCADO Y SUS IMPLICACIONES NORMATIVAS*
}

Andrea Alarcón Peña**

Fecha de recepción: 1 de septiembre de 2014

Fecha de evaluación: 30 de enero de 2015

Fecha de aprobación: 24 de octubre de 2015

Artículo de reflexión

DOI: http://dx.doi.org/10.18359/prole.1683

Forma de citación: Alarcón, A. (2016). La libre competencia económica en el derecho colombiano: una revisión desde la economía social de mercado y sus implicaciones normativas. Revista Prolegómenos Derechos y Valores, 19, 37, 109-124. DOI: http://dx.doi.org/10.18359/prole.1683

\section{Resumen}

El artículo consigna un ejercicio de revisión jurídica sobre las características del modelo de economía social de mercado, reconocido como modelo económico por la Corte Constitucional, dentro del subsistema constitucional económico colombiano. La primera parte del escrito detalla las particularidades e implicaciones de este modelo y las consecuencias que su estructura supone para la libre competencia económica, habida consideración del marco normativo de protección. Posteriormente, se describen las generalidades de los sistemas de protección del derecho a la competencia anglosajón y europeo tomando como referencia las normas más importantes en cada uno de ellos, con el fin de comprender el impacto que dichos sistemas tuvieron en el modelo colombiano. Por último se presentan las propiedades más relevantes del régimen de protección de competencia en Colombia a partir de un bosquejo general del marco normativo existente.

\section{Palabras clave:}

Mercado, Estado social de derecho, libre competencia, competencia desleal, prácticas restrictivas.

\footnotetext{
El presente artículo es resultado del proyecto de investigación No. 1492 "El derecho a la libre competencia en la constitución económica colombiana" financiado por la Vicerrectoría de Investigaciones de la Universidad Militar Nueva Granada (UMNG, Bogotá, Colombia) año 2014. El proyecto forma parte del Centro de Investigaciones de la Facultad de Derecho de la UMNG.

** Abogada cum laudem y especialista en Derecho Comercial y de los Negocios de la Universidad Santo Tomás, Bogotá, Colombia. Magíster en Derecho Económico de la Universidad Externado de Colombia, Bogotá, Colombia. Candidata a doctora en Estudios Jurídicos, Ciencia Política y Criminología de la Universidad de Valencia, Valencia, España. Docente de planta de la Facultad de Derecho de la Universidad Militar Nueva Granada. Correo electrónico: andrea.alarcon@unimilitar. edu.co
} 


\title{
FREE ECONOMIC COMPETENCE IN COLOMBIAN LAW: A REVIEW FROM THE SOCIAL ECONOMY OF MARKET AND ITS NORMATIVE IMPLICATIONS
}

\begin{abstract}
Summary
The article consigns a juridical review exercise about the features of the model of market social economy, recognized as economy model by the Constitutional Court inside the Colombian economical constitutional subsystem. The first part of the writing details the particularities and implications of this model and the consequences that this structure represents for the free economic competence, previously considering the protection normative frame. Afterwards, there are described the Anglo-Saxon and European generalities of protection systems of right to competence taking as a reference the most important norms in each one of them, in order to understand the impact that such systems had on Colombian model. Finally, there are presented the most relevant properties of the competence protection regimen in Colombia from a general outline of the existing normative frame.
\end{abstract}

\section{Keywords:}

Market, social State of law, free competence, unfair competence, restrictive practices.

\section{A LIVRE CONCORRÊNCIA ECONOMICA NO DIREITO COLOMBIANO: UMA REVISÃO DA ECONOMIA SOCIAL DE MERCADO E SUAS IMPLICAÇÕES NORMATIVAS}

\begin{abstract}
Resumo
O artigo apresenta um exercício de revisão jurídica sobre as características do modelo de economia social de mercado, reconhecido como o modelo econômico pela Corte Constitucional, dentro do subsistema constitucional econômico colombiano. A primeira parte do descrito detalha as particularidades e implicações deste modelo e as consequências impostas para a livre concorrência econômica, levando em consideração o marco normativo de proteção. Posteriormente, será descrito as generalidades dos sistemas de proteção de direito à concorrência anglo-saxônica e europeia, tomando como referencia as normas mais importantes de cada um, com a finalidade de compreender o impacto dos referidos sistemas no modelo colombiano. Enfim, são apresentadas as características mais relevantes do regime de proteção à concorrência na Colômbia a partir esboço geral do marco normativo em voga.
\end{abstract}

Palavras-chave:

Mercado, Estado social de direito, concorrência, concorrência desleal, práticas restritivas. 


\section{Introducción}

En la investigación de la que se deriva el presente artículo, se pretende acreditar cuáles son las características que el derecho a la libre competencia económica supone en el marco de un Estado social de derecho, cuáles sus requisitos y qué limitaciones pueden predicarse desde el supuesto de la existencia de un esquema de intervención estatal en el desarrollo económico. La investigación emplea un enfoque cualitativo, con uso del método documental y analizando las peculiaridades que en Colombia tiene el derecho a la libre competencia económica a partir de la descripción de los dos sistemas de protección a la libre competencia más importantes: el anglosajón y el europeo.

Precisar las particularidades del modelo económico plasmado en la Constitución de 1991 requiere una descripción previa del modelo de Estado que acoge al primero. El Estado social de derecho impone una serie de principios, valores y reglas de obligatorio cumplimiento y materialización efectiva. Esta nueva acepción permeó al subsistema constitucional económico combinando elementos libertarios con otros de corte intervencionista. Esta combinación ha generado conflictos entre derechos y libertades que han sido ponderados en el marco de una economía social de mercado.

Este subsistema encuentra referentes valiosos en la legislación norteamericana y europea que han influido en el modelo de protección de la libre competencia que adoptó Colombia. La materialización del principio en comento supone la expedición de normas que castiguen actos que restrinjan esta libertad y órganos encargados de hacerlo efectivo.

\section{A. Subsistema constitucional econó- mico colombiano}

El subsistema constitucional económico, entendido como un conjunto de normas de contenido económico dentro del enramado constitucional, supone para el caso colombiano un modelo de economía social de mercado (Dalla, 2006).

La economía social de mercado no es un sistema económico que se halle prescrito por el constituyente colombiano. Se trata más bien de un sistema que reconoce la Corte Constitucional y la Constitución colombiana ${ }^{1}$ a partir del análisis sistemático de los principios, libertades y preceptos de contenido económico que contempla. Sus orígenes pueden remontarse a las décadas de los veinte y treinta en Alemania con la teoría de la Escuela de Friburgo como respuesta a la crisis económica del Estado que se dio a mediados del siglo XIX.

No será la pretensión de este artículo describir los rasgos de la economía social de mercado, sino indicar cuál ha sido el tratamiento que la libre competencia económica ha tenido en Colombia desde el modelo que la Corte Constitucional ha descrito como el que consigna la Constitución económica o el denominado subsistema constitucional económico.

No se trata en consecuencia, de un estudio que pretenda determinar si la economía social de mercado es el modelo que se ajusta a la Constitución de 1991. Será entonces esta una premisa base de la que partiremos y que permitirá a su vez, considerar que la libre competencia económica como garantía, hace posible el funcionamiento de una economía de mercado en la medida en que facilita la concurrencia de agentes económicos al mercado para, en igualdad de condiciones, poder ofrecer bienes y servicios.

\section{B. Orígenes de la economía social de mercado}

Con la Segunda Guerra Mundial la economía social de mercado empezó a ser el sistema económico que sirvió de inspiración a varias de las constituciones económicas europeas ${ }^{2}$. Sus

\footnotetext{
1 Múltiples sentencias permiten colegir esta posición, consúltense, entre otras: C-148/2015, C-263/2011, C-535/1997, C-620/2011, C-837/2013 y C-1045/2000.

2 No es propio, sin embargo, expresar que este es el mo-
} 
orígenes pueden remontarse a la Escuela de Friburgo que parte de la consideración tradicional de dos modelos de ordenación de la economía: economía central y economía de mercado.

No obstante, estima que la segunda es la única que puede ser compatible con un modelo de Estado social de derecho. Y ello es así en tanto que el Estado asume un papel mucho más activo en la regulación y ordenación de la economía después de los años treinta. No se puede olvidar que la crisis económica de 1929 en los Estados Unidos permeó todo el sistema económico mundial y produjo consecuencias importantes respecto al abandono del sistema liberal puro, caracterizado por la confianza absoluta en el mercado, la consagración de garantías constitucionales económicas mínimas (propiedad privada y libertad de comercio e industria) y la limitación a las posibilidades interventoras del Estado en el orden económico.

El concepto "economía social de mercado" lo analizó con precisión el economista alemán Alfred Müller-Armack (1963). Las ideas base para sus reflexiones provinieron de la Escuela de Friburgo que desde los años cuarenta, de manera secreta, adelantó estudios sobre reconstrucción económica después de la guerra. Müller-Armack no formó parte de la Escuela de Friburgo ${ }^{3}$, pero

delo económico que acoge la Constitución alemana, el Tribunal Constitucional alemán es enfático en indicar que su Constitución, desde el punto de vista económico, es neutra y por ende permite la coexistencia de modelos económicos diversos, siempre y cuando no contradigan los principios y valores fundamentales que expone la Ley Fundamental. Para mayor claridad véanse las sentencias del 20 de julio de 1954 (Ley de Ayuda a la Inversión) y del 1 de marzo de 1979 (Ley de Cogestión de los Trabajadores). Para el caso español, el Tribunal Constitucional, en sentencia del 28 de enero de 1982, decretó que su Constitución es neutra y que, siguiendo la postura alemana "no sanciona ni garantiza necesariamente un sistema económico único y determinado, sino que más bien permite el funcionamiento de todos los sistemas que se ajusten a los parámetros constitucionales; solo excluye aquellos programas de Gobierno que sean contradictorios con estos".

3 En este punto se encuentran posiciones disímiles. Por un lado están los que consideran que Müller-Armack fue un miembro de la Escuela de Friburgo, sin embargo para Tezuka (2002) esto no fue posible, pues para los hizo uso de varias de sus ideas para cimentar y desarrollar el concepto de economía social de mercado (Tezuka, 2002). A esta ideología se le asocia con la categoría de "ordoliberal" propia de la escuela a que hemos hecho mención.

El ordoliberalismo surge como una respuesta a las políticas intervencionistas que se desataron en Europa a partir de las décadas de los años veinte y treinta. No obstante, fue con la Segunda Guerra Mundial que tomó relevancia. El ordoliberalismo parte de la "teoría del ordo" y la "teoría de la interdependencia de los ordos"; ordo representa el atributo principal que tienen las personas: libertad, y las cosas: naturaleza. El ordo será entonces la conjunción de estas y representará la libertad natural, que aplicada al sistema económico, supondrá que la economía perseguirá el principio de libertad de toda una sociedad.

Para el ordoliberalismo la libertad es el principio más importante en la sociedad (incluida entonces la esfera económica) y en consecuencia, la ordenación de la economía sí es un asunto del que deben ocuparse las instituciones que estructuran y dan forma al Estado, se abandona por tanto la idea liberal clásica (Maestro, 2002). El ordoliberalismo comprende que la ordenación de la economía es un problema político respecto del cual las entidades públicas están llamadas a cumplir un papel fundamental (Bárcena, 2011).

Con estas premisas, la economía social de mercado se caracteriza por matizar los postulados del liberalismo clásico que confiaba en la autonomía del mercado y su facultad autorregulatoria. La necesidad de regular e intervenir en el mercado, con el fin de garantizar objetivos superiores del Estado, precisa de un rol mucho más activo de este.

\section{Economía social de mercado en la Constitución colombiana}

El proceso constitucional colombiano de 1991 demostró que el Estado no puede ser indiferente

años cincuenta Müller-Armack se había trasladado de Münster a Colonia. 
a las relaciones económico-sociales. Se ajusta a la tendencia del constitucionalismo propio de la posguerra que permeó en buena parte de los textos constitucionales al incorporar, de forma diversa, la estructuración del orden económico. $\mathrm{Y}$ al tenor de los textos constitucionales (Alemania y España) que sirvieron de inspiración al colombiano, el constituyente optó por un sistema económico neutro que, a pesar de esta característica, debe tener en cuenta principios, valores y disposiciones dispersas en todo el texto constitucional que describen un sistema económico en particular: la economía social de mercado.

Este sistema constitucional ${ }^{4}$ supone una ordenación de la economía que implica ponderar unos elementos libertarios aunados a algunos componentes intervencionistas ${ }^{5}$. Esta combina-

4 Aunque ante esta expresión y la de Dalla (2006) es pertinente considerar que la Corte Constitucional en sentencia C-398/1995 indicó que "la Carta Política no ha acogido un modelo económico determinado, exclusivo y excluyente, y en que sus normas deben ser interpretadas de manera armónica y coherente, evitando posiciones absolutas, por lo cual la libertad del individuo se encuentra atemperada en la preceptiva constitucional por la prevalencia del interés colectivo (art. 1), por las competencias de intervención y regulación a cargo del Estado (C. N. arts. 333, 334 y 335) y por los principios de razonabilidad y proporcionalidad que la doctrina de esta Corte ha prohijado".

5 El artículo 314 de la Carta Política señala que el Estado tiene a su cargo la dirección general de la economía, disposición que le permite participar en ciertas áreas determinadas (por ejemplo servicios públicos), a su vez el artículo 333 garantiza el libre ejercicio de la actividad económica y de la iniciativa privada-dentro de los límites del bien común-asegurando la libre competencia económica a todos los agentes que participen en el mercado. Con el ánimo de garantizar este postulado, el Estado -dotado de facultades intervencionistas en la economía-puede desarrollar acciones que impidan la restricción de las libertades económicas y el abuso de la posición dominante. No obstante, esta libertad económica no es absoluta, puede ser objeto de delimitaciones cuando lo exija el interés social, el medioambiente y el patrimonio cultural de la nación. Para profundizar en este aspecto es pertinente revisar el análisis que hace Pinzón (2010, pp. 67-71) de la igualdad en el derecho constitucional y su perspectiva a la luz de la nueva economía institucional (NEI). La NEI es a su vez una de las escuelas más relevantes del Análisis Económico del Derecho (AED), a la que se suma la Escuela de Chicago, la de New Haven y la Escuela de la Elección Pública -Public Choice-. ción obedece a los distintos modelos económicos acogidos por la Constitución: el modelo capitalista o de libre mercado, el sistema socialista y los sistemas mixtos (Leguizamón, 2002). El modelo de economía de mercado colombiano conlleva el análisis de varios elementos, que reúnen variadas premisas ${ }^{6}$ :

1. Principio pro libertad.

2. Principio pro igualdad.

3. Unidad de mercado, pluralidad de actores.

4. Intervención pública económica.

5. Principio de la libre competencia.

6. Principios y derechos económicos sociales.

A la luz de Giraldo (2011) se advierte la concurrencia de otras garantías o "asuntos económicos" en la Constitución que se ligan al derecho al trabajo, la participación en la producción de los trabajadores y a la participación de estos en la gestión empresarial al tenor del artículo 53 de la CP.

Considerando el objeto del documento, es pertinente puntualizar en el análisis de los principios de igualdad y libertad, por estar asociados ellos con la iniciativa económica y la libre competencia. En ese sentido, es imperativo indicar que la igualdad a garantizar es real, material o sustancial (Quinche, 2011) y debe predicarse con relación a todas las personas o actores económicos (naturales o jurídicos) que intervienen en el mercado. El nuevo espíritu teleológico de la igualdad debe vincularse con otros conceptos como el de desarrollo sostenible, interés general, utilidad pública, medioambiente sano, solidaridad, defensa y protección del patrimonio cultural, etc. (Mesa de Promoción y Defensa de la Constitución de 1991, 1999).

06 Jorge Enrique Ibáñez (1998) reconoce que el sistema económico colombiano se asienta en varias premisas: (i) garantía y respeto de los derechos económicos o aquellos que puedan estar dotados de un contenido económico; (ii) existencia de una economía de mercado con responsabilidades para los agentes que intervienen en el mismo y (iii) intervención del Estado en la actividad económica. 
El principio de igualdad en el marco económico, impone al Estado la obligación de promoverlo efectivamente. La consagración del mismo le exige adoptar las decisiones y políticas públicas necesarias para dotar a todos los agentes económicos de un mínimo de condiciones que les faciliten acceder en forma efectiva a las garantías económicas constitucionales previstas. El Estado abandona su papel de espectador del orden económico para inmiscuirse en el mismo y desplegar las acciones que sean oportunas (Banco de la República, 1998). La cláusula progresista que penetra el modelo constitucional debe adjetivarse de un contenido económico que se equilibra con la justicia social ${ }^{7}$.

Así, y relacionados con el principio de igualdad en materia económica, encontramos varios postulados constitucionales presentados como derechos y libertades: derecho de propiedad (arts. 60 y 64); libertad económica y de empresa (art. 333); derecho al trabajo (art. 25); derecho a la libre elección de oficio o profesión (art. 26); derecho a la libertad sindical y huelga (art. 55); derecho de asociación (art. 38); derecho a la libre competencia económica y a la iniciativa privada (art. 333); derecho de la comunidad a que el Estado vele por la capacidad adquisitiva de la moneda (art. 373); derecho de los consumidores y usuarios a la calidad de los bienes y servicios recibidos (art. 78) y derecho de la comunidad a que se inspeccione, vigile y controle a aquellos que realizan actividades económicas (arts. 333 y 334). No obstante, el planteamiento de estos derechos supone su ponderación y articulación con objetivos generales del Estado y derechos de otros agentes dentro del mercado que podrían entrar en conflicto (Correa, 2009). Este conflicto se da en forma concreta entre los siguientes derechos:

7 Sin embargo, al hacer mención de este argumento es preciso reportar que la instauración de un catálogo de derechos al amparo del Estado social de derecho en la Constitución colombiana conlleva unos recursos importantes que el constituyente no consideró, circunstancia que en palabras de Cuéllar (2005) no ha sido problema en la mayoría de sentencias del máximo tribunal constitucional. Surge entonces la necesidad de idear alternativas que permitan conciliar el gasto que representa cumplir los mandatos constitucionales con el modo en que se obtienen los recursos para su financiación.
1. Derecho a la propiedad (uso, goce y disposición, arts. 58, 61 y 332) vs. función social de la propiedad y limitaciones en caso de interés general (art. 58).

2. Economía de mercado y defensa de la competencia (art. 333) vs. posibilidad de la ley para regular e intervenir en la economía y el mercado (art. 333).

3. Libertad de empresa (art. 334) vs. establecimiento de monopolios y restricción a particulares para ejercer ciertas actividades económicas (art. 336).

Respecto al principio de libertad económica, este se bifurca y hallamos la libre iniciativa por un lado y la libre actividad económica por otro, las dos sujetas al bien común. La libre competencia económica como un derecho de todos que supone responsabilidades ${ }^{8}$. La libertad de empresa sujeta a la función social que la acompaña y el consecuente deber del Estado de impedir restricciones que obstruyan la libertad económica y evitar el abuso de posiciones dominantes en el mercado9.

Al incorporar este último postulado se reconoce la existencia de competencia imperfecta dentro del mercado, la existencia de externalidades (Cuevas, 2004), la inexistencia de óptimos abso-

8 Este derecho puede ser protegido por vía de las acciones contenidas en el artículo 88 de la Constitución Política.

9 El constituyente de 1991 expresó: "Por eso, a la vez que la Comisión ha propuesto promover la internacionalización de la economía colombiana, sobre las bases de la equidad y conveniencia nacional, no ignoramos las exigencias propias de la dimensión de los factores productivos para competir en las condiciones características de un mercado ampliado. Ni tampoco, conscientes de los resultados obtenidos en la experiencia europea, proponemos que la concentración sea reprimida per se sino cuando conlleve abusos de la posición dominante en el mercado. En adición, algunos de los miembros de la Comisión consideraron conveniente completar ese texto con la frase que aparece entre paréntesis de tal manera que se señale al legislador su obligación de dotar al Gobierno de instrumentos para controlar la concentración de poder económico cuando esta perjudique a la comunidad. Esta adición se orienta al control de acciones de los conglomerados económicos, antes que al simple abuso de posiciones dominantes en uno u otro mercado individual" (Marulanda et al., 1991, págs. 15). 
lutos en la distribución de recursos, la existencia de prácticas restrictivas de la competencia ${ }^{10} \mathrm{y}$ finalmente la necesidad de articular el modelo económico nacional con las exigencias de un sistema globalizante (Rubio, 2007).

La libertad económica es un derecho de libre configuración del legislador, es un derecho constitucional no fundamental que admite limitaciones que se puedan derivar de la intervención del Estado en la economía ${ }^{11}$; aunque considerando que cualquier limitación debe atender a criterios de razonabilidad y no arbitrariedad ${ }^{12}$. Esta libertad tiene un ingrediente adicional que la cualifica en la medida en que es una herramienta que favorece el desarrollo de las libertades individuales independientemente de que se trate de una libertad de todos.

Libertad para acceder, permanecer y retirarse del mercado cuando se estime conveniente -siempre y cuando no se trate de actividades calificadas como servicios públicos o de interés público, como el servicio de acueducto, alcantarillado, energía, etc.-. Libertad para estable-

10 Las prácticas restrictivas de la competencia aparecen en las leyes 155/1957 y 1340/2009.

11 Aunque Leguizamón (2002) indica que la Constitución de 1991 es más rigurosa al determinar que la ley es el único medio idóneo para adelantar intervención económica, esta apreciación debe atemperarse con medios adicionales mediante los cuales el Estado ejerce su función de intervención en la economía. La primera posibilidad de intervención se efectúa a través de normas (leyes, decretos -por ejemplo los expedidos en Estados de excepción, artículos 212, 213 y 215 de la $\mathrm{CP}-$, resoluciones, etc.), aunadas a estas encontramos: intervención del Banco de la República (como banca central), intervención a través del Plan Nacional de Desarrollo (arts. 341 y ss. de la $\mathrm{CP}$ ), intervención mediante las funciones de inspección, vigilancia y control asignadas a las superintendencias (algunas de ellas dotadas de facultades jurisdiccionales), intervención mediante organismos de control del medioambiente (corporaciones autónomas regionales), intervención por medio de los organismos de fomento económico (como el Consejo Nacional de Competitividad), entre otras. Al respecto, véase sentencia C-478/1992.

12 La Corte Constitucional en sentencia C-384/2003 señaló que además de las tradicionales restricciones a la libertad económica y la libre competencia: prevalencia del bien común, interés público, debía adicionarse la protección de los usuarios del sistema financiero. cerse y organizarse económicamente y manejar recursos empresariales, valorados estos como dimensiones de la libertad positiva, limitadas y no absolutas sujetas a autodeterminación y autocomposición. Libertad negativa en tanto que el Estado no puede restringir u obstruir la libertad personal, salvo casos de conflicto de derechos previa ponderación (fricción entre las libertades económicas) (T-468/2003).

Hasta ahora se ha abogado por la preeminencia de una igualdad sustancial, sin embargo el principio de igualdad formal no ha quedado del todo superado, es menester indicar que cuando se determinan requisitos, reglas $\mathrm{u}$ obligaciones para acceder al mercado, prestar determinados servicios y otras condiciones similares, estos deben ser iguales y ser acatados por todos los agentes en el mercado, así, la ordenación del mercado ha de ser unitaria y esto se traduce en eficiencia.

Por todas las razones expuestas existe un marco jurídico que busca garantizar la efectividad de la igualdad y libertad como bases del subsistema constitucional económico, así en materia de derecho de la competencia el marco regulador contempla las leyes 155/1959, 256/1996 y $1340 / 2009$, el decreto $2153 / 1992$ y las circulares externas 10/2001 y 11/2001 de la Superintendencia de Industria y Comercio (SIC).

En cuanto al derecho del consumidor, el marco regulador aún es ineficiente, lo que supone que la brecha por reequilibrar la situación de desventaja en que se halla el consumidor debe ser objeto de análisis profundo, es evidente que el consumidor-usuario de un bien o servicio está en desventaja debido a una asimetría de información con relación al productor-distribuidor. La ley 1480/2011 intenta satisfacer esta pretensión, pero ha sido la jurisprudencia ${ }^{13}$ la que se

13 Al respecto, se cita la sentencia C-1141/2000 (M. P.: Eduardo Cifuentes Muñoz) que en cuanto a la protección del consumidor indicó: "La Constitución ordena la existencia de un campo de protección en favor del consumidor, inspirado en el propósito de restablecer su igualdad frente a los productores y distribuidores, dada la asimetría real en que se desenvuelve la persona 
ha encargado de ahondar en la defensa de los derechos de los consumidores ${ }^{14}$.

Estas dos normas contemplan a su vez acciones para los diversos agentes económicos, orientadas a "restablecer el equilibrio" en el mercado. Las acciones colectivas intentan satisfacer esta pretensión ${ }^{15}$.

\section{Antecedentes en la legislación internacional de las normas de protección a la competencia y a la libre competencia económica: el caso Estados Unidos y Unión Europea}

La política antimonopolio o antitrust ${ }^{16}$ nació en los Estados Unidos con el fin de defender la libre competencia, evitar las concentraciones de capital en desmedro de las virtudes del mercado

que acude al mercado en pos de la satisfacción de sus necesidades humanas. Sin embargo, la Constitución no entra a determinar los supuestos específicos de protección, tema este que se desarrolla a través del ordenamiento jurídico. El programa de protección, principalmente, se determina a partir de la ley, los reglamentos y el contrato"; y la sentencia C-909/2012 (M. P.: Nilson Pinilla) en la cual se admite la necesidad de proteger al consumidor constitucionalmente, pues dicha protección "Se inspira en el deber de fortalecer sus derechos frente a los productores y distribuidores, dada la desigualdad y la asimetría en que se desenvuelve la persona que acude al mercado de cualquier bien o servicio, para satisfacer sus necesidades". También hay referentes jurisprudenciales adicionales en las sentencias C-749/2009 y C-973/2002, entre otras.

14 Además existen otras que constituyen el marco normativo a tener en cuenta al hablar de derecho del consumidor, entendido este como el agente más débil en la relación comercial, así: leyes 73/1981 y 640/2001, decretos 1441/1981, 493/2001, 147/1999, 1485/1996, 3466/1982 y 2876/1984.

15 A pesar de esta mención, Parra (1998) aduce que se deben utilizar nuevas técnicas procesales para que el consumidor logre la protección de sus derechos y la satisfacción de sus pretensiones con mayor rapidez y eficacia. Reconoce el autor que el mecanismo de protección consignado en el decreto 3466/1982 se emplea poco y el procedimiento es moderno (se basa en la class action del sistema norteamericano).

16 El trust recibe este nombre por un tipo de asociación comercial: trustees ship, mediante el cual se permite consolidar el control de empresas a través de la transferencia de acciones a cambio de certificados sobre el trust. Así, las empresas concernidas lograban eliminar la competencia al tener el control legal de las industrias (sobre todo las manufactureras y mineras) (Botero, 2002).
(Agudelo, 1999) y fomentar el bienestar de los consumidores. Esta política está integrada, para el caso de los Estados Unidos, por varias normas que por la estructura del sistema common law han sido fortalecidas a través de diversos pronunciamientos judiciales, estas son: Sherman Antitrust Act expedida en el año 1890, Clayton Act del año 1914, la Federal Trade Commission Act del mismo año; la Robinson-Patman Act de 1936, la Celler-Kefauver Act de 1950 y la HartScott-Rodino Antitrust Improvements Act de 1976 (estas tres últimas enmiendas a las primeras) ${ }^{17}$.

Además de esta mención, es importante tener en cuenta que para el sistema constitucional estadounidense la política de defensa de la libre competencia es uno de los principios estructurales de su sistema político, al considerar que uno de los pilares de una "democracia fuerte" es una "economía fuerte", pues esta favorece el bienestar general y permite la posibilidad de competir en el mercado (Álvarez, 2000). Tal nivel de relevancia registra la normativa norteamericana sobre la competencia que las leyes antitrust en general y la Sherman Antitrust Act en particular, constituyen las reglas fundamentales de la protección a la libre empresa.

Estas disposiciones son el cimiento de la política de competencia en los Estados Unidos e irradian el ordenamiento económico mundial. Las normas que consignan estos preceptos son de tipo prohibitivo, se trata de un derecho que mediante un número limitado de prohibiciones reprime conductas (pasivas y activas) desarrolladas por agentes económicos.

La Sherman Antitrust Act, pilar de la legislación antitrust, se divide en dos secciones que contienen proscripciones referidas a las prácticas restrictivas del comercio y a las conductas monopólicas. Esta ley condena el monopolio y prohíbe los carteles ${ }^{18}$.

17 Además de las mencionadas, Botero (2002) señala la existencia de estatutos federales especiales aplicables a ciertos sectores de la industria: Federal Aviation Act, Federal Communication Act, Webb-Pomerene Act, Wilson-Gorman Tariff Act y The Revenue Act (legislación antidumping).

18 Los carteles o conspiracies, el entendimiento o acuerdo entre rivales para determinar precios más elevados a los 
Posteriormente la Clayton Act pretendió enriquecer a su antecesora consignando, de forma precisa, un listado de conductas ilegales debido a que su predecesora no especificaba cuáles eran las conductas precisas que eran objeto de prohibición, permitiendo así gran discrecionalidad para los operadores jurídicos que con el amparo de la "regla de la razón" (rule of reason) declaraban que las restricciones razonables al comercio eran legales.

Este criterio, al amparo de la nueva legislación, fue modificado por el enfoque per se: son condenados todos los acuerdos o contratos que restringen el comercio sin excepción alguna. A pesar de la clara intención de esta disposición, no se consignaron sanciones penales que incentivaran su cumplimiento, las mismas se circunscribían a una indemnización de perjuicios (sanciones de tipo civil).

La Federal Trade Commission Act creó la Federal Trade Commission, ente administrativo responsable de la vigilancia del cumplimiento de la legislación antitrust norteamericana. Se le atribuyó a esta comisión la titularidad en el ejercicio del derecho de acción, sustrayendo a los particulares de la facultad de iniciar procesos judiciales. No obstante esta disposición, los particulares pueden emprender acciones civiles privadas cuando hayan sido perjudicados en su empresa o en su propiedad con ocasión de la violación de normas antitrust. Las normas restantes apuntan a modificaciones o adiciones de los preceptos acá explicados.

ordinarios con el fin de aprovecharse o apropiarse de las utilidades que tal comportamiento genera. Barón (2010) expresa que los empresarios agrupados mantienen su independencia jurídica y económica con relación a lo concertado. Los integrantes del cartel obtienen estos beneficios a través de la reducción de la producción y la consiguiente elevación de los precios, convirtiéndose así en agentes económicos con posición de dominio al fijar precios y cantidades en el mercado. Sin embargo, en este punto hay que tener en cuenta que por tratarse de un acuerdo sin fundamento legal o contractual ante el incumplimiento que del mismo haga uno de los integrantes no existen posibilidades para ejecutar el cumplimiento de este. A su vez, se generan incentivos para que futuros competidores ingresen al mercado y ofrezcan productos sustitutos o similares con mejores precios y cantidades afectando la oferta y las bases del cartel.
Es preciso recordar que con relación a la legislación antimonopolio en los Estados Unidos, dos escuelas relacionadas con el AED han realizado aportes significativos orientados a definir límites a la intervención del Estado para controlar el fenómeno de la integración y concentración de capitales y mercado: la Escuela de Harvard y la Escuela de Chicago. La primera de ellas considera que la concentración del mercado genera comportamientos negativos por parte de los agentes económicos, justifica entonces la existencia de una legislación antitrust estructural.

Por el contrario, la Escuela de Chicago reconoce que deben estudiarse los objetivos de la concentración, dependiendo de los intereses perseguidos es posible calificar como eficiente a este fenómeno. La concentración entonces debe ser reprimida, solamente, si genera efectos negativos mayores que los efectos positivos alcanzados. Es decir, acoge la regla de la razón como criterio para calificar la ilegalidad de un acuerdo o contrato entre agentes económicos, apuntando a la maximización de la eficiencia como única justificación de una legislación antitrust (Botero, 2002).

La aplicación de la regla de la razón o rule of reason era acogida por la Escuela de Chicago, que preveía un análisis ex post de la realización de la conducta y la aplicación de la regla per se era tomada por la Escuela de Harvard, que partía de la calificación de prohibidos de cualquier tipo de conducta contraria a la libre competencia económica; esto es, partía de una regulación ex ante.

Las dos escuelas en comento se encontraban en dos extremos en lo que respecta a intervención. Ahora bien, Estados Unidos ha abogado por la generación de mercados competitivos con claras restricciones a la intervención pública (Sendín, 2003). Esa política sin embargo, fue objeto de revaluación a partir del caso Enron y, más recientemente, de la crisis en el sector financiero y asegurador norteamericano ${ }^{19}$.

19 Ravassa (2004) al citar a López señala que la posición adoptada por la Escuela de Harvard se mantuvo hasta los años setenta, mientras que a partir de esa década la 
Estos antecedentes de la legislación estadounidense irradiaron la legislación de la Unión Europea. El Tratado Constitutivo de la Comunidad Económica Europea (de ahora en adelante TCE), expedido el 25 de marzo de 1975 en Roma, contempla en forma expresa en sus artículos $81,82,85$ y 86 la sanción y represión a conductas contrarias a la libre competencia económica al interior de la Unión Europea.

El artículo 81 menciona las prácticas o acuerdos concertados entre agentes económicos (empresas o asociaciones de empresas, quedando incluidos los grupos empresariales y cualquier otro operador económico) "que tengan por objeto impedir, restringir o falsear el juego de la competencia dentro del mercado común [...]”. Esta disposición prevé la declaratoria de nulidad de pleno derecho de prácticas colusorias que persigan los objetivos citados; sin embargo, el numeral 3 de dicho artículo establece excepciones que podrían alegar las empresas o agentes económicos para justificar la práctica sin que sean sometidas a un procedimiento sancionatorio.

Circunstancia importante que debe ser objeto de mención a partir de la redacción del artículo 81 del TCE, es la amplitud con que consideran los acuerdos entre empresas, estimando inclusive la posibilidad de gentlemen `s agreement o pacto de caballeros ${ }^{20}$.

El artículo 82 por su parte prohíbe "la explotación abusiva [...] de una posición dominante en el mercado común o en una parte sustancial del mismo", disposición que se asemeja a la consignada en el artículo 333 inciso 4 de la CP. Los artículos 81 y 82 del TCE fueron regulados por el reglamento 1/2003 de la Comisión Europea. A través de este reglamento se le confieren competencias investigativas y sancionatorias a la Comisión. A diferencia del procedimiento norteamericano, en la Unión Europea la investigación

Escuela de Chicago ha dado prioridad a la eficacia como objetivo principal de la intervención y la regulación en materia de políticas antitrust.

20 Acuerdos verbales entre agentes económicos que carecen de soporte legal y se basan solamente en la palabra de honor de los participantes. por una violación al TCE en los artículos pertinentes puede ser iniciada de oficio o a petición de parte (denuncia de un tercero).

El artículo 85 prohíbe de forma expresa los carteles y los acuerdos verticales y horizontales que pudieran realizar empresas tales como fijación de precios, límites a la cantidad producida, acuerdos de exclusividad y compra y venta en común (Barón, 2010). El artículo 86 proscribe los abusos de posición dominante al interior del mercado, circunstancia para la cual se tiene en cuenta el estudio del mercado relevante (compuesto por el mercado producto y el mercado geográfico que son analizados al momento de hacer estudios de integraciones económicas).

Del articulado en referencia se colige que al interior de la Unión Europea se aboga por un modelo de competencia eficaz sustentado en la existencia de un número limitado de competidores, empresas sólidas y ampliamente calificadas, contrario a un modelo de competencia atomística (Ravassa, 2004). Es decir, el modelo europeo propende por evitar la generación de barreras a la entrada de futuros competidores y el norteamericano, por su parte, se centra en controlar el poder de mercado -ligado a monopolios- ${ }^{21}$.

Vistas entonces las características del sistema norteamericano y del sistema europeo se puede desprender una de las principales diferencias existentes entre ellas y que radica en el fin perseguido; mientras que el sistema europeo regula el monopolio, el norteamericano lo prohíbe. Es decir, el segundo es preventivo y el primero correctivo. El sistema estadounidense señala que la política antimonopolio debe reservarse para los peores abusos del poder de mercado; esto es, incentiva un mundo liberalizado en el cual las barreras a la entrada son bajas y los mercados están abiertos a la competencia interna y externa (Samuelson $\&$ Nordhaus, 2002). En el caso colombiano es importante reconocer que los monopolios, entendidos como una falla en el mercado, son prohibidos por el constituyente (art. $336 \mathrm{CP}$ )

21 Para profundizar véase Amador (2010). 
y solo podrán existir como arbitrios rentísticos del Estado. Aunque existe la posibilidad de que por disposición legal, administrativa o judicial se permita a un agente económico explotar de manera absoluta y exclusiva un bien o servicio determinado por un lapso establecido ${ }^{22}$.

El articulado que se contempla en el TCE constituye referente significativo para el análisis del marco normativo colombiano relacionado con prácticas restrictivas de la competencia y actos de competencia desleal.

\section{E. El modelo de la libre competencia colombiano}

Con posterioridad a la celebración del Tratado de Roma, surge en Colombia el primer antecedente de legislación promotora de la competencia en el país: la ley 155/1959. A las disposiciones que la integran las influye la legislación europea y norteamericana. Con un marco normativo adecuado y eficiente se garantiza que los consumidores puedan tener acceso a una variedad de productos y servicios provenientes de numerosos agentes que ofrezcan mejores precios.

Esta afirmación la refuerza el célebre profesor Shyam Khemani (1993), quien advertía la necesidad de una regulación en este sentido, por cuanto.

Las empresas tienen incentivos para adquirir poder sobre el mercado, o sea, para obtener un control discrecional sobre los precios y otros factores asociados que determinan las transacciones comerciales. Este poder sobre el mercado puede surgir limitando la competencia por medio de la imposición de barreras al comercio y/o legalización de arreglos colusorios para restringir los precios y la productividad y otras prácticas que generalmente se consideran como un fracaso del mercado, ocasionando una repartición

22 Es posible entonces considerar las licencias, concesiones, reconocimiento de derechos derivados de la propiedad industrial, áreas de servicios exclusivos y otras que se constituyen en verdaderas barreras de entrada al mercado. ineficiente de recursos y afectando adversamente el rendimiento de la industria y el bienestar socioeconómico.

Esta realidad es la que justifica la existencia de normas que promuevan e incentiven la competencia en el mercado, con el fin de evitar ineficiencias e inequidades que afectan directamente el bienestar de los agentes que intervienen en cualquier sector de la economía.

La ley 155/1959 consigna en su articulado prohibiciones expresas a prácticas restrictivas de la competencia y disposiciones relacionadas con el trámite aplicable a ciertas integraciones empresariales que cumplieran con algunos requisitos aludidos en la misma, amén de las sanciones que para los agentes económicos pudiera generar incurrir en cualquiera de estas actuaciones. Con respecto a la primera mención: prácticas restrictivas de la competencia, el artículo primero es preciso al prohibir acuerdos o convenios que tengan por objeto (directo o indirecto) limitar la libre competencia o mantener precios inequitativos ${ }^{23}$.

El artículo primero de la norma en cita abarca la totalidad del proceso productivo, desde el momento mismo de la producción hasta la distribución de mercancías, materias primas, servicios o productos nacionales o extranjeros. El legislador intentó incorporar en ese artículo la totalidad de los comportamientos prohibidos o restringidos a los agentes económicos, en un claro aprendizaje de las falencias consignadas en la Sherman Antitrust Act y satisfechas por la Clayton Act.

Sin embargo, dicha disposición en su parágrafo único legitima al Gobierno para autorizar acuerdos o convenios, que no obstante constituir limitaciones o restricciones a la libre competencia, den estabilidad a un sector básico de interés para la

\footnotetext{
23 Artículo primero modificado por el artículo primero del decreto 3307/1963: "Quedan prohibidos los acuerdos o convenios que directa o indirectamente tengan por objeto limitar la producción, abastecimiento, distribución o consumo de materias primas, productos, mercancías o servicios nacionales o extranjeros, y en general, toda clase de prácticas, procedimientos o sistemas tendientes a limitar la libre competencia y a mantener o determinar precios inequitativos".
} 
economía nacional. Hasta el año 2009 este parágrafo no había sido desarrollado, aunque con expedición de la ley 1340/2009, se indicó que el sector agropecuario recibiría tal calificativo, otorgando competencia al Ministerio de Agricultura y Desarrollo Rural para calificar previamente la celebración de cualquier acuerdo o convenio que apunte en esa dirección.

Esta intención, a su vez encuentra satisfacción en el artículo 12 de la ley 1340/2009 a través de la excepción de eficiencia que permite a la autoridad correspondiente autorizar la operación cuando los interesados acrediten que los beneficios para los consumidores exceden los posibles efectos negativos que la operación podría ocasionar sobre la competencia ${ }^{24}$.

La ley 1340/2009 a su vez, somete a vigilancia del Estado a las empresas que ostenten posición de dominio ${ }^{25}$ en el mercado. A partir de esta disposición, fue necesario abordar el concepto de mercado, relevante para poder determinar si un agente tenía posición de dominio en el mercado, concepto que además era indispensable al momento de analizar integraciones empresariales, como contempla la norma en su artículo $4^{26}$. Este artículo incorporó la necesidad de someter a control y aprobación previa de

24 Sin embargo, en este caso es indispensable que los interesados acompañen un compromiso en el cual garanticen que los efectos positivos serán trasladados a los consumidores o usuarios.

25 La SIC ha señalado con relación a la posición de dominio en el mercado, que la misma se presenta cuando un agente económico controla, efectiva o potencialmente, el mercado relevante obstruyendo u obstaculizando la competencia. Advierte además que dichos agentes económicos, prevalidos de dicha condición, actúan con independencia o sin consideración real del comportamiento de sus competidores, clientes o consumidores. Este calificativo solo puede ser posible una vez se analicen tres condiciones: (i) definición de mercado relevante, (ii) determinación de la posición de la empresa en el mercado sectorial y (iii) análisis de la posibilidad con que cuentan los competidores, actuales o potenciales, para debilitar la posición de dominio (SIC, concepto 1001016 de febrero de 2001).

26 Determinar la existencia de posición dominante era asunto de los supervisores en cada uno de los sectores del mercado. la $\mathrm{SIC}^{27}$, so pena de nulidad por objeto ilícito, las integraciones empresariales ${ }^{28}$ entre agentes económicos-empresas ${ }^{29}$-. Este concepto previo debía ser proferido por la SIC, con excepción hecha de las empresas vigiladas por la Superintendencia Financiera -disposición modificada por la ley 1340/2009 en su artículo 930 . A su vez, el parágrafo 3 del artículo 4 modificado por la norma mencionada, señalaba la exención que se hacía respecto a las empresas que integraran un grupo económico de comunicar la integración empresarial ${ }^{31}$. En estos casos no

27 Esta disposición fue adoptada en la ley 1340/2009 con el propósito de evitar conflictos de competencia o decisiones proferidas por supervisores diferentes frente a un mismo caso. Valga la pena recordar el célebre caso de la Alianza-Sam y Aces que inicialmente fue objetada por la SIC y luego fue aprobada por la Superintendencia de Puertos y Transporte.

28 Las integraciones empresariales que deben comunicarse a la superintendencia no se predican de todas las empresas o agentes económicos. Solo deben reportarse aquellas que cumplan con los siguientes requisitos: (i) las compañías deben dedicarse a la misma actividad económica o participar en la misma cadena de valor (vertical u horizontalmente); (ii) en conjunto o individualmente consideradas hayan tenido en el año fiscal anterior a la operación proyectada ingresos operacionales superiores al monto determinado por la SIC; o (iii) cuando las empresas en conjunto o individualmente en el año fiscal anterior a la operación hayan tenido activos superiores al monto que haya señalado la SIC. A su vez, los interesados deben contar con más del 20 $\%$ del mercado relevante (ley 1340/2009, art. 9).

29 La definición de empresa que acoge la legislación pro competencia en el país es la que se consigna en el artículo 25 del Código de Comercio colombiano que reza: "Se entenderá por empresa toda actividad económica organizada para la producción, transformación, circulación, administración o custodia de bienes, o para la prestación de servicios. Dicha actividad se realizará a través de uno o más establecimientos de comercio". Para más información sobre el concepto de empresa véase Castro (s. f.).

30 Aunque no existe, la decisión es adoptada por la Superintendencia Financiera de Colombia, que debe solicitar análisis a la SIC sobre el efecto que una operación en este sentido pudiera tener en la libre competencia económica. La SIC podrá, en estos casos, sugerir condicionamientos a la operación que garanticen la preservación de la competencia en el mercado.

31 En los términos del artículo 28 de la ley 222/1995: "Habrá grupo empresarial cuando además del vínculo de subordinación, exista entre las entidades unidad de propósito y dirección. Se entenderá que existe unidad 
existe la obligación de comunicar la integración a la superintendencia correspondiente.

El marco normativo de la legislación pro competencia se complementa con la ley 256/1996 que reprime los actos de competencia desleal ${ }^{32}$. Esta ley incluye una multiplicidad de actos que protegen a los competidores de conductas que atenten contra la buena fe que debe caracterizar a los negocios mercantiles, entre ellos: actos de engaño, de confusión, de inducción a ruptura contractual, de descrédito, de desviación de clientela, de imitación, de publicidad engañosa; violación de secretos, pactos desleales de exclusividad y una cláusula general que engloba a todas aquellas conductas que tengan por objeto o como efecto restringir la libre competencia económica.

Este ordenamiento evidencia de manera general las conductas que limitan la competencia, es necesario entonces, mencionar que la legislación colombiana incluye disposiciones expresas en torno a sectores específicos del mercado. Así, y por mencionar un ejemplo, en el sector de los servicios públicos domiciliarios las disposiciones, por la naturaleza misma de la actividad, que protegen la libre competencia tienen un sentido propio. Buena parte de estas disposiciones amén de salvaguardar la libre competencia, protegen a los consumidores, pues las violaciones a esta libertad perjudican de modo ostensible a los usuarios.

Las leyes 142/1994 y 143/1994 se "empeñaron en estimular la competencia" incorporando un sistema "de regulación y control de las situaciones

de propósito y dirección cuando la existencia y actividades de todas las entidades persigan la consecución de un objetivo determinado por la matriz o controlante en virtud de la dirección que ejerce sobre el conjunto, sin perjuicio del desarrollo individual del objeto social o actividad de cada una de ellas".

32 El artículo 7 de la ley 256/1996 determina que "constituye competencia desleal, todo acto o hecho que se realice en el mercado con fines concurrenciales, cuando resulte contrario a las sanas costumbres mercantiles, al principio de la buen fe comercial, a los usos honestos en materia industrial o comercial. O bien cuando esté encaminado a afectar o afecte la libertad de decisión del comprador o consumidor, o el funcionamiento concurrencial del mercado". de monopolio en el mercado de los servicios públicos domiciliarios" (Sánchez, Pacheco, Obregón \& Alvarado, 2001, p. 27).

La ley 143/1994 se empeña en promover la libre competencia y evitar actos de competencia desleal o abuso de posición dominante en el mercado. Sin embargo, reconoce la existencia de monopolios a través de las denominadas áreas de servicio exclusivo. El decreto 2153/1992 complementa este ordenamiento normativo consignando en su artículo 2 numerales 1 a 5 un catálogo de atribuciones que competen a la SIC vinculadas con la promoción de la libre competencia y prácticas restrictivas de la misma; imponer sanciones por prácticas comerciales restrictivas y actos de competencia desleal; y velar por la observancia de las disposiciones que atañen al régimen de protección de los usuarios. En este momento, y para la generalidad del mercado, es la SIC el organismo responsable de tramitar procedimientos administrativos diversos contra aquellos agentes que infrinjan reglas sobre protección a la competencia.

Estas normas en apariencia se ocupan principalmente de los agentes económicos que intervienen en el sector, aunque la Constitución Política de manera directa establece un régimen de protección para los usuarios de los servicios públicos domiciliarios, decretando así que el derecho de la competencia y el derecho del consumo serán dos caras de la misma moneda, como afirma el profesor Palacios (1999, p. 168): "existe no solo un derecho a competir cuyo titular es el empresario, sino un derecho cuyos titulares son todos los consumidores de bienes y servicios".

Esta disposición encuentra soporte en el artículo 369 CP que menciona la obligación que compete al legislador para determinar el régimen de derechos y protección de los usuarios. Así, el artículo 2 de la ley 142/1994 consigna dentro de los nueve fines de la intervención del Estado en el sector de los servicios públicos domiciliarios, ocho dirigidos a la protección de los derechos y garantías de los usuarios, habida consideración del fin especial que cumplen los servicios públicos domiciliarios para garantizar la eficacia 
de los derechos de los habitantes del territorio nacional. Los preceptos en mención otorgan al regulador la función de fijar un marco regulatorio que además de garantizar la libre competencia, la promueva y estimule.

La ley 142/1994 se debe complementar en su análisis con el decreto 2153/1992. Para el caso concreto de los acuerdos contrarios a la libre competencia, el artículo 47 del decreto en comento se articula con el 34 de la ley 142/1994, en la medida en que este último mandato contempla de manera enunciativa y no taxativa aquellos acuerdos que lesionen la libre competencia. Por ejemplo:

6. Los que tenga por objeto o tengan como efecto la limitación de los desarrollos técnicos; 7. Los que tenga por objeto o tenga como efecto subordinar el suministro de un producto a la aceptación de obligaciones adicionales que por su naturaleza no constituían objeto del negocio, sin perjuicio de lo establecido en otras disposiciones; los que tengan por objeto o tenga como efecto abstenerse de producir un bien o servicio o afectar sus niveles de producción.

Además de estos podríamos referir actos que supongan infracción a normas de publicidad (en clara protección de los derechos de los usuarios) o la influencia que podría hacerse frente a una empresa competidora para que desista de rebajar sus precios o se niegue a vender o prestar servicios a otra empresa.

En cuanto al caso de los actos de competencia desleal, vale la pena señalar que el artículo 34.5 de la ley 142/1994 realiza una remisión expresa y directa a la ley $256 / 1996$, preceptos que entonces serán aplicables directamente a las empresas competidoras que realicen actividades en el sector (Ramírez, 2003).

\section{Conclusiones}

El proyecto de investigación arroja las siguientes consideraciones respecto al derecho a la libre com- petencia económica en un modelo de economía social de mercado (acogido constitucionalmente), y sus implicaciones en torno a los actos de competencia desleal y las prácticas restrictivas de la competencia en el caso colombiano:

- El modelo económico constitucional colombiano permite armonizar derechos y libertades que aparentemente podrían entrar en conflicto.

- La intervención del Estado en la economía obedece entonces a la necesidad de evitar actos que vulneren derechos (fundamentales o colectivos) de aquellos que concurren al mercado como oferentes o destinatarios finales de un bien o servicio.

- Garantizar el ejercicio del derecho a la libertad e igualdad hace posible la concreción y efectividad de las garantías económicas de raigambre constitucional.

- La libertad de empresa, reconocida por el ordenamiento constitucional, admite la existencia de competencia imperfecta dentro del mercado, la existencia de externalidades, la inexistencia de óptimos absolutos en la distribución de recursos, la existencia de prácticas restrictivas de la competencia ${ }^{33} \mathrm{y}$ finalmente, la necesidad de articular el modelo económico nacional con las exigencias de un sistema globalizante.

- El sistema norteamericano de protección de competencia es preventivo y el europeo es correctivo. El primero señala que la política antimonopolio debe reservarse para los peores abusos del poder de mercado, es decir, incentiva un mundo liberalizado en el cual las barreras a la entrada son bajas y los mercados están abiertos a la competencia interna y externa.

33 Las prácticas restrictivas de la competencia se encuentran contenidas en las leyes 155/1957 y 1340/2009. 
- La normativa de protección a la competencia económica, como un derecho constitucional colectivo, garantiza a los consumidores y en general a todos aquellos que intervengan en el mercado, la existencia de cláusulas que avalen la concurrencia y participación en condiciones de mediana igualdad para cualquier agente económico.

- El marco normativo colombiano en materia de protección a la competencia económica, no se caracteriza por la concurrencia de múltiples reglamentos que dificulten su armonización y aplicación. Hay sectores que tienen disposiciones normativas especiales pero su interpretación no resulta ser farragosa.

\section{Referencias}

Agudelo, H. (1999). De los monopolios a la democracia económica. Una política para controlar la concentración del poder económico. Bogotá.

Ariel Economía.Álvarez, S. M. (2000). La inesperada funcionalidad de un derecho constitucional: el derecho de petición de la primera enmienda estadounidense $y$ la defensa de la libre competencia. En F. Sosa. El derecho administrativo en el umbral del siglo XXI. Homenaje al Prof. Dr. Ramón Martín Mateo (pp. 2.766). Valencia: Tirant lo Blanch.

Amador, L. E. (2010). Constitución de 1991, competencia y servicios públicos domiciliarios. Contexto: Revista de Derecho y Economía, 28, pp. 9-43.Banco de la República. (1998). Introducción al análisis económico. El caso colombiano. Bogotá: Siglo del Hombre Editores.

Bárcena, J. D. (2011). El gobierno de la economía europea. Crisis e indeterminación institucional. Vol. 3. Barcelona: JM Bosch Editor.

Barón, G. A. (2010). El derecho de la competencia en los grupos empresariales. Bogotá: Grupo Editorial Ibáñez.
Botero, C. (2002). El derecho antitrust o de la libre competencia en los Estados Unidos. Medellín: Librería Seña Editora.

Castro, M. (s. f.). Derecho comercial. Actos de comercio, empresas, comerciantes y empresarios. Bogotá: Uniandes, Temis.

Correa, M. (2009). Libertad de empresa en el Estado social de derecho. Bogotá: Universidad Externado de Colombia.

Cuéllar, M. M. (2005). La prueba de razonabilidad y la estabilidad de las reglas de juego. Bogotá: Centro de Estudios sobre Desarrollo Económico, Facultad de Economía, Universidad de los Andes.

Cuevas, H. (2004). Fundamentos de la economía de mercado ( $2^{\mathrm{a}}$ ed.). Bogotá: Universidad Externado de Colombia.

Dalla, A. R. (2006). Derecho constitucional económico ( $2^{\mathrm{a}} \mathrm{ed}$.). Buenos Aires: Lexis Nexis.

Giraldo, G. F. (2011). Participación ciudadana en la toma de decisiones. En J. Stefan. 20 años de la Constitución colombiana. Logros, retrocesos y agenda pendiente ( $\mathrm{p}$. 233). Bogotá: Opciones Gráfficas Editores.

Ibáñez, J. E. (1998). Los derechos de los consumidores y usuarios: fundamentos constitucionales y desarrollo legal. En: M. Velilla. Política y derecho del consumo (pp. 59-133). Bogotá: El Navegante Editores.

Khemani, S. (1993). Objetivos de la política de competencia. Revista Planeación y Desarrollo, XXIV(2).

Leguizamón, W. (2002). Derecho económico. Fundamentos. Bogotá: Ediciones Doctrina y Ley.

Maestro, G. (2002). Constitución económica e integración europea. Revista de Derecho Político, 54, pp. 33-111.

Marulanda, I., Perry, G., Benítez, J., Cuevas, T., Garzón, A. \& Guerrero, G. (1991). Régimen económico. Libertad de empresa, competencia económica, monopolios e 
intervención del Estado. Informe de ponencia. Comisión Quinta. Bogotá: Secretaría General Asamblea Nacional Constituyente.

Mesa de Promoción y Defensa de la Constitución de 1991. (1999). Construyendo democracia. Bogotá: Corporación Viva la Ciudadanía.

Müller-Armack, A. (1963). Economía dirigida y economía de mercado. (E. Hernandez Esteve, Trad.) Madrid: Sociedad de Estudios y publicaciones.

Palacios, H. (1999). El derecho de los servicios públicos. Bogotá.

Parra, J. (1998). Mecanismos judiciales de protección al consumidor. En: M. Velilla. Política $y$ derecho del consumo (pp. 427-440). Bogotá: El Navegante Editores.

Pinzón, M. A. (2010). Arreglos institucionales y la igualdad en el derecho económico constitucional. Contexto: Revista de Derecho y Economía, pp. 67-75.

Quinche, M. F. (2011). Derecho constitucional colombiano. Bogotá: Universidad del Rosario.

Ramírez, J. (2003). Régimen legal de la competencia en los servicios públicos domiciliarios. Revista de Derecho Universidad del Norte de Barranquilla, pp. 92-134.

Ravassa, G. J. (2004). Derecho mercantil internacional. Normas y principios. Bogotá: Doctrina y Ley.

Rubio, J. (2007). Derecho de los mercados. Bogotá: Legis.

Rubio, M. (2007). Derecho y economía (1 ${ }^{\text {a }}$ ed.). Bogotá: Universidad Externado de Colombia.

Samuelson, P. A. \& Nordhaus, W. D. (2002). Economía (17 ed.). Madrid: McGraw-Hill, Interamericana de España.

Sánchez, G., Pacheco, H., Obregón, G. \& Alvarado, Y. (2001). Del carácter singular del derecho de la competencia en los servicios públicos domiciliarios. En: S. d. Domiciliarios. Actualidad jurídica. Tomo IV. Bogotá: SSPPDD.
Sendín, M. A. (2003). Regulación y servicios públicos ( $1^{\mathrm{a}}$ ed.). Granada: Comares.

Tezuka, M. (2002). The economic reconstruction plan of Alfred Müller-Armack: what is the social market economy? En: S. Yuichi. The German Historical School (pp. 202-214). Londres: Routledge, Taylor \& Francis Group.

Sentencias

\section{Corte Constitucional}

Sentencia C-478/1992. M. P.: Eduardo Cifuentes Muñoz.

Sentencia C-535/1997. M. P.: Eduardo Cifuentes Muñoz.

Sentencia C-1045/2000. M. P.: Álvaro Tafur Galvis.

Sentencia C-1141/2000. M. P.: Eduardo Cifuentes Muñoz.

Sentencia C-973/2002. M. P.: Álvaro Tafur Galvis.

Sentencia C-384/2003. M. P.: Clara Inés Vargas Hernández.

Sentencia T-468/2003. M. P.: Rodrigo Escobar Gil.

Sentencia C-749/2009. M. P.: Luis Ernesto Vargas Silva.

Sentencia C-263/2011. M. P.: Jorge Ignacio Pretelt Chaljub.

Sentencia C-909/2012. M. P.: Nilson Pinilla.

Sentencia C-837/2013. M. P.: Luis Ernesto Vargas Silva.

Sentencia C-148/2015. M. P.: Gloria Stella Ortiz Delgado.

\section{Tribunal Constitucional alemán}

Sentencia de 20 de julio de 1954. Ley de Ayuda a la Inversión.

Sentencia de 1 de marzo de 1979. Ley de Cogestión de los Trabajadores.

\section{Tribunal Constitucional español}

Sentencia de 28 de enero de 1982. 